\title{
CURRÍCULO E INCLUSÃO ESCOLAR: UM OLHAR SOBRE O ENSINO RELIGIOSO E AS RELIGIÕES DE MATRIZ AFRICANA NO AMAPÁ ${ }^{1}$
}

\section{Curriculum and school inclusion: a look at religious education and religions of African matrix in Amapá}

\section{Elivaldo Serrão Custódio²}

\begin{abstract}
Resumo:
O presente artigo tem por objetivo analisar o currículo e a inclusão escolar do Ensino Religioso no Amapá. O texto traz um enfoque para a o Ensino Religioso e as Religiões de Matriz Africana na educação pública estadual. Trata-se de um estudo exploratório de natureza qualitativa onde foi utilizado como investigação a pesquisa bibliográfica, a análise documental e a entrevista semiestruturada. Os resultados da pesquisa apontam que na educação pública estadual há uma variedade de opções de trabalho sobre essa temática, ora revelando um discurso inovador, ora refletindo práticas tradicionais, conservadoras ou proselitistas. Há indícios de que a diversidade religiosa não tem sido considerada dentro das ações dos órgãos oficiais do governo e que há grandes dificuldades em se concretizar um diálogo concreto. Muitos técnicos/as e gestores/as desconhecem os elementos que compõem o fenômeno religioso e o papel das tradições religiosas na sociedade. Palavras-chave: Currículo; Inclusão Escolar; Ensino Religioso; Matriz Africana; Amapá.
\end{abstract}

\section{Abstract:}

This article aims to analyze the curriculum and school inclusion of Religious Education in Amapá. The text focuses on African-based Religious Education and Religions in state public education. This is an exploratory study of qualitative nature, which was used as research bibliographic research, document analysis and semi-structured interview. The research results show that in the state public education there are a variety of work options on this theme, sometimes revealing an innovative discourse, sometimes reflecting traditional, conservative or proselytizing practices. There are indications that religious diversity has not been considered within the actions of official government bodies and that there is great difficulty in achieving a concrete dialogue. Many technicians and managers are unaware of the elements that make up the religious phenomenon and the role of religious traditions in society.

Keywords: Curriculum; School Inclusion; Religious Education; African Matrix; Amapá.

$$
* * *
$$

1 Enviado em: 01.07.2018. Aceito em: 21.03.2020.

2 Pós-Doutor em Educação pela Universidade Federal do Amapá (UNIFAP). Doutor em Teologia pela Faculdades EST, em São Leopoldo/RS. Mestre em Direito Ambiental e Políticas Públicas pela Universidade Federal do Amapá. Pedagogo, Matemático e Teólogo. Vice-líder do Grupo de Pesquisa Educação, Interculturalidade e Relações ÉtnicoRaciais (UNIFAP/CNPq). Editor Associado da Revista Identidade da Faculdades EST. Atualmente é professor permanente no Mestrado em Educação (PPGED/UNIFAP) e professor do Curso de Pedagogia da Faculdade Madre Tereza em Santana/Amapá/Brasil. E-mail: elivaldo.pa@hotmail.com.

Protestantismo em Revista | São Leopoldo | v. 45, n. 02 | p. 37-48| Jul./dez. 2019

Disponível em: <http://periodicos.est.edu.br/index.php/nepp> 


\section{Introdução}

Analisar o currículo e a inclusão escolar no Brasil sob uma perspectiva crítica das relações étnico-raciais não é uma tarefa fácil, isto porque o país apresenta uma autoimagem de uma nação racialmente democrática. Verificando a realidade de negros/as e brancos/as em várias dimensões da vida, torna-se perceptível que estes sempre estiveram em posições desiguais, em relação às oportunidades.

Compreendendo o currículo escolar como um dispositivo de controle discursivo - todo sistema de educação é uma maneira política de manter ou de modificar a apropriação dos discursos, com os saberes e os poderes que eles trazem consigo ${ }^{3}$, - o qual busca constituir sujeitos para um determinado tipo de sociedade, passou-se a refletir sobre quais discursos do ER circulariam em torno dos órgãos governamentais e não governamentais do Estado, e de que forma poderiam constituir sujeitos - Identidades. ${ }^{4}$

Assim, o presente artigo tem por objetivo analisar o currículo e a inclusão escolar do Ensino Religioso no Amapá. O texto traz um enfoque para a o Ensino Religioso e as Religiões de Matriz Africana na educação pública estadual. Trata-se de um estudo exploratório de natureza qualitativa onde foi utilizado como investigação a pesquisa bibliográfica, a análise documental e a entrevista semiestruturada.

Na primeira parte deste trabalho serão abordados o caminho metodológico da pesquisa. Em seguida, será apresentada uma análise dos dados pesquisados do Ensino Religioso (ER) e das Religiões de Matriz Africana (RMA) no currículo escolar da educação pública estadual no Amapá. Posteriormente, o texto traz algumas percepções e ações sobre o ER; Percepções e ações sobre RMA. E por fim, as considerações finais.

\section{Caminho metodológico da pesquisa}

No presente estudo exploratório de natureza qualitativa foi utilizado como método de investigação a pesquisa bibliográfica, a análise documental e a entrevista semiestruturada. A pesquisa foi desenvolvida com base nos pressupostos e fundamentos da dialética. ${ }^{5}$ Optou-se por uma pesquisa crítico-dialética, com discussões amparadas na análise de Discurso (AD). A entrevista semiestruturada foi realizada com os gestores e/ou técnicos de órgãos governamentais e não governamentais, vinculados ou não a Secretaria Estadual de Educação do Amapá (SEED). Privilegiouse a pesquisa qualitativa, por permitir compreender melhor como os gestores, técnicos e/ou professores da disciplina de ER constroem e reconstroem seus saberes e fazeres ao levar em conta os aspectos religiosos e as relações étnico-raciais em seu cotidiano escolar.

Os sujeitos envolvidos nas entrevistas receberam uma codificação a fim de garantir o anonimato. Optamos por determiná-los de interlocutores no corpo do trabalho, adicionando-lhes, após o uso do termo, uma letra maiúscula do alfabeto. Nisto, os interlocutores foram classificados de $A$ até $L$. Os interlocutores A e B não foram entrevistados segundo o roteiro de perguntas

3 FOUCAULT, Michel. A ordem do discurso: Aula inaugural no Collège de France em 02 de dezembro de 1970. 16a Ed. Tradução de Laura Fraga de Almeida Sampaio. São Paulo: Loyola, 2008, p. 44; DEMO, Pedro. Metodologia Científica em Ciências Sociais. 3. Ed. São Paulo: Atlas, 2009.

4 SILVA, Tomaz Tadeu. Documentos de identidade: Uma introdução às teorias do currículo. 3. Ed. Belo Horizonte: Editora Autêntica, 2003.

5 SEVERINO, Antônio Joaquim. Metodologia do Trabalho Científico. 23. Ed. São Paulo: Cortez, 2007.

Protestantismo em Revista | São Leopoldo | v. 45, n. 02 | p. 37-48| Jul./dez. 2019

Disponível em: <http://periodicos.est.edu.br/index.php/nepp> 
semiestruturadas. O roteiro foi utilizado para elucidar algumas questões específicas sobre tal funcionamento e deliberações dos seus respectivos órgãos junto SEED.

Partindo da premissa de que o pesquisador pode assumir imagens múltiplas e que os seus praticantes assumem o compromisso de uma prática interpretativa ${ }^{6}$, optou-se, inicialmente, por delimitar nossa pesquisa de campo. O critério utilizado foi o de ocupação do cargo e seu grau de importância na hierarquia da gestão ao órgão vinculado, além do grau de autonomia e participação que esses gestores, técnicos e/ou representantes possuem no processo de tomada de decisões sobre os assuntos que dizem respeito as PE para o componente curricular ER e para as RMA no currículo escolar na educação pública estadual no Amapá.

Sendo assim, os entrevistados se restringiram a apenas um (01) participante, num total de onze (11) sujeitos (gestor/a, técnico/a e/ou representante legal) de cada um dos seguintes órgãos: Coordenadoria de Desenvolvimento e Normatização das Políticas Educacionais (COODNOPE/SEED), Núcleo de Assessoramento Técnico-pedagógico (NATEP/SEED); Unidade de Currículo e Supervisão Escolar (UOCUS/SEED); Núcleo de Educação Étnico-Racial (NEER/SEED); Associação de Professores do ER do Estado do Amapá (APERAP); Conselho Estadual de Educação do Amapá (CEE/AP); Secretaria de Estado da Cultura do Amapá (SECULT), Secretária Extraordinária de Políticas Afrodescendentes (SEAFRO); União dos Negros do Amapá (UNA) e representante das RMA cadastrado para representar as entidades religiosas no Estado do Amapá perante a COODNOPE/SEED. Ressalta-se que todos os sujeitos que concederam a entrevista, agiram com cordialidade e educação. Vejamos o quadro contendo os dados dos entrevistados:

\section{Quadro 1: Caracterização do grupo de entrevistados}

\begin{tabular}{|c|c|c|c|c|c|}
\hline Nome Fictício & Representante & $\begin{array}{c}\text { Cor ou } \\
\text { Raça }\end{array}$ & Religião & $\begin{array}{c}\text { Id } \\
\text { ad } \\
\text { e }\end{array}$ & Formação Acadêmica \\
\hline Interlocutor A & COODNOPE $^{7}$ & Negra & Católica & 54 & Lic. Em História \\
\hline Interlocutor B & NATEP 8 & Parda & Católica & 43 & Lic. Em Pedagogia \\
\hline Interlocutor C & UOCUS & Branca & Católica & 44 & Lic. Em Letras e Pedagogia \\
\hline Interlocutor D & NEER & Negra & $\begin{array}{l}\text { Não se } \\
\text { manifestou }\end{array}$ & 37 & Lic. Em História \\
\hline Interlocutor $\mathrm{E}$ & APERAP & Negra & Católica & 47 & $\begin{array}{l}\text { Lic. Em História e Ensino } \\
\text { Religioso }\end{array}$ \\
\hline Interlocutor F & CEE/AP & Pardo & Cristã & 40 & Lic. Em Ciências da Religião \\
\hline Interlocutor G & SECULT & Preta & Católico & 54 & Lic. Educação Física e Pedagogia \\
\hline Interlocutor $\mathrm{H}$ & $\begin{array}{c}\text { SEAFRO - GT } \\
\text { EDUCAÇÃO }\end{array}$ & Negra & Católica & 49 & Lic. Em Educação Física \\
\hline Interlocutor I & SEAFRO - GT RMA & Pardo & Umbanda & 27 & Lic. Em História \\
\hline Interlocutor J & UNA & Preta & Católico & 50 & Bacharel em Direito \\
\hline Interlocutor L & RMA-LIRA & Preta & Candomblé & 50 & Teólogo \\
\hline
\end{tabular}

Fonte: CUSTÓDIO (2014). Pesquisa realizada no período de abril a novembro de 2013.

É bom frisar que a análise das informações foi processada com a finalidade de garantir uma captação complexa, contraditória e concreta, das mesmas entre si e com a totalidade na qual estão inseridas, garantindo assim uma síntese coerente e coesa da realidade. O referencial teórico usado

6 DENZIN, Norma K.; LINCOLN, Yvonna S. Introdução: a disciplina e a prática da pesquisa qualitativa. In: DENZIN, Norma K. O planejamento da pesquisa qualitativa: teorias e abordagens. 2. ed. Porto Alegre: Artmed, 2006. p. 17.

7 O interlocutor foi entrevistado parcialmente para efeito de informações complementares.

8 O interlocutor foi entrevistado parcialmente para efeito de informações complementares.

Protestantismo em Revista | São Leopoldo | v. 45, n. 02 | p. 37-48| Jul./dez. 2019 
neste trabalho foi, durante todas as etapas desta pesquisa, extremamente importante para detectar indícios de racismo, de discriminação e de intolerância religiosa por parte de algumas instituições pesquisadas, pois forneceu instrumentos que possibilitaram a percepção das outras dimensões do racismo - as sutilezas no âmbito dos afetos, das emoções, dos valores.

Destaca-se que entre os entrevistados a religião predominante exercida e/ou praticada é a católica, com exceção dos Interlocutores I e L que fazem parte das RMA. Em relação à questão da cor, quanto aos representantes (Quadro 1), os entrevistados sobre sua cor/raça ficaram livres para respondê-los através do preenchimento dos dados pessoais, para implicitamente reconhecermos características como racismo ou preconceito.

No entanto, notou-se que três entrevistados não utilizaram da definição de branca ou negra, atribuíram-se como "parda", característica de identificação mais sutil vivido na sociedade colonial escravista com o objetivo de produzir efeitos positivos de identidade com reflexos até os dias atuais. ${ }^{9}$ Outro fator importante que destaca-se é em relação a idade dos entrevistados, pois a maioria tem mais de quarenta anos e todos com formação superior. Sobre a experiência profissional, percebe-se que a maioria (06 entrevistados) tem mais de vinte anos de experiência na área da educação pública. Isto implica no fato de que estes profissionais, em tese, possuem uma rica experiência e conhecimento no desenvolvimento de ações voltadas as PE das relações étnicoraciais.

\section{Análise de dados: do ensino religioso e das religiões de matriz africana no currículo escolar da educação pública estadual no Amapá}

As falas dos entrevistados foram divididas de forma a apresentar-se as diversas visões em relação às temáticas abordadas. O que se pretende a partir de agora é saber como esses gestores/as, técnicos/as e/ou representantes legais de cada um dos órgãos ora mencionados lidam com tais questões, o que pensam do assunto e o que fazem enquanto gestores/as. A entrada no campo de pesquisa, inicialmente, foi junto a SEED, para análise do ER e as RMA no currículo escolar da educação pública estadual no Amapá. Verificamos que em relação ao cumprimento da Lei Federal $n^{\circ} 10.639 / 2003$, somente a partir do ano de 2008, incluiu-se como obrigatório o Ensino da Cultura e História Africana e Afro-brasileira no currículo da educação básica do sistema de ensino estadual, apesar das disposições previstas na CF desde 1988.

No tocante ao componente curricular ER, com base nos documentos oficiais e nas entrevistas, verifica-se que se o Ensino da Cultura e História Africana e Afro-brasileira no currículo escolar da educação básica estadual não foi devidamente enfatizado e/ou contemplado. Ademais, percebe-se que a religiosidade afro-brasileira se encontra inserida de forma tímida no diálogo entre o campo das PE do Ensino da Cultura Afro-brasileira, especialmente, no currículo escolar do ER. A partir da premissa de que o estudo da cultura afro-brasileira é uma PE de Estado ${ }^{10}$, portanto, obrigatória, o reconhecimento das RMA na disciplina de ER. Para tanto, é necessário que o educador - aqui nos referindo a todos os profissionais em educação - deva ser preparado para lidar com a

9 VIANA, Larissa. O Idioma da mestiçagem: as irmandades de pardos na América Portuguesa. Campinas: Editora da UNICAMP, 2007.

10 AITH, Fernando. Políticas públicas de Estado e de governo: instrumentos de consolidação do Estado Democrático de Direito e de promoção e proteção de direitos humanos. In: AITH, Fernando; BUCCI, Maria Paula Dallari (Org.) Políticas Públicas: reflexões sobre o conceito jurídico. São Paulo: Saraiva, 2006, p. 217-246.

Protestantismo em Revista | São Leopoldo | v. 45, n. 02 | p. 37-48| Jul./dez. 2019

Disponível em: <http://periodicos.est.edu.br/index.php/nepp> 
temática das relações étnico-raciais, no currículo da educação básica, para que não promovam a repetição e a inculcação de uma cultura legítima em desfavor de outras. ${ }^{11}$

Pelas palavras dos entrevistados, observa-se que na educação pública estadual no Amapá, não existe por parte dos órgãos oficiais (SEED, SEAFRO, SECULT), interesse em promover PE para a inclusão da RMA no currículo escolar do ER, bem como a capacitação dos educadores sobre RMA, pois de acordo com as declarações da maioria dos entrevistados, as RMA ainda são vistas com certo receio e/ou discriminação na educação pública estadual. Pela análise documental, corroborada pelas entrevistas, observa-se que há descaso por parte dos órgãos governamentais na efetividade de PE e qualidade de ensino para o ER na educação pública do Estado do Amapá e que o direito do ER está tão-somente sob a responsabilidade do segmento cristão. De acordo com as afirmações da maioria dos entrevistados, as RMA ainda são vistas com certo receio e/ou discriminação na educação pública estadual.

Na pesquisa verificou-se ainda que as RMA possuem tratamento diferenciado, bem como aparecem com menor grau de representatividade e/ou importância explícita na prática curricular. Essa afirmativa reforça a não observância das regras do ensino da cultura e da história afro brasileira, que estão previstas no artigo 26-A da Lei de Diretrizes e Bases da Educação Nacional (LDBEN) de 1997. ${ }^{12}$ Importa salientar que o documento que trata da Base Nacional Comum Curricular (BNCC), contempla, de forma geral, as temáticas relativas à cultura africana e afrobrasileira, em conformidade à legislação (Leis $\left.n^{\circ} 10.639 / 2003\right) .{ }^{13}$ Dentre vários pontos, merece destaque a ênfase na história da diversidade étnico-racial e cultural da população brasileira, bem como as articulações da história do Brasil com a história local e mundial. Espera-se que o documento de implementação da BNCC seja um norte para uma melhor qualidade da educação brasileira. Porém, acreditamos que se não estiver acompanhado por uma política educacional participativa, com condições de infraestrutura e tecnologia adequada, bem como uma maior consideração e valorização da formação e atuação desses profissionais, a proposta será somente mais um documento dentre tantos que já foram formulados e discutidos pela sociedade brasileira. ${ }^{14}$

\section{Percepções e ações sobre o ensino religioso}

Sobre os conteúdos do ER da rede pública estadual do Amapá, percebe-se que há um entendimento comum dos entrevistados quanto à definição destes. A maioria (05 entrevistados) respondeu que quem define ou deveria definir esses conteúdos é a própria SEED, através do seu corpo técnico. Um dos entrevistados respondeu que esses conteúdos eram definidos pela SEED, em conjunto por uma comissão formada por professores em reuniões num espaço cedido pela Arquidiocese da Igreja Católica de Macapá-AP. Embora três (03) entrevistados tenham declarado que não tinham informação ou conhecimento a respeito desta questão, um (01) entrevistado destacou:

11 BOURDIEU, Pierre; PASSERON, Jean-Claude. A reprodução: elementos para uma teoria do sistema de ensino. Tradução de Reynaldo Bairão. 3. ed. Petrópolis: Vozes, 2008.

12 BRASIL. Lei no 9.475, de 22 de julho de 1997. Brasília, 1997. Dá nova redação ao art. 33 da Lei no 9.394, de 20 de dezembro de 1996, que estabelece as diretrizes e bases da educação nacional. Disponível em: <http://www.planalto.gov.br/ccivil03/Leis/L9475.htm>. Acesso em: 09 mar. 2011.

13 BRASIL. Lei no 10.639, de 09 de janeiro de 2003. Brasília, 2003. Instituiu a obrigatoriedade do ensino de História e Cultura Afro-brasileira e Africana no Currículo da Educação Básica. Disponível em: <http://www.planalto.gov.br/ccivil03/Leis/2003/L10.639.htm>. Acesso em: 01 out. 2011.

14 BRASIL. Ministério da Educação (MEC). Base Nacional Comum Curricular, Brasília: 2018.

Protestantismo em Revista | São Leopoldo | v. 45, n. 02 | p. 37-48| Jul./dez. 2019 
Olha, é uma pergunta, um tanto quanto complexa de responder [risos], porque não há interesse nenhum para nada no ensino religioso [enfática]. Quem define, embora haja documentos como as diretrizes curriculares do Estado, lá têm quais os conteúdos que se devam trabalhar. Essas diretrizes são esquecidas [...] (INTERLOCUTOR E).

A afirmativa denota que não estão sendo cumpridas e/ou observadas o que diz a nova redação do artigo 33 da LDBEN (Lei no 9.475/1997) onde estabelece em sua redação oficial que o ER é parte integrante da formação básica do cidadão, assegurando o respeito à diversidade cultural e religiosa do Brasil, vedado qualquer forma de proselitismo. A afirmação da LDBEN, ao proibir o proselitismo religioso, é bem explícita, pois, o ER não deve ser confundido com educação religiosa, não sendo razoável o ER confessional nas escolas públicas. A confessionalidade ameaça à justiça religiosa, não promove a diversidade, não garante a igualdade ente os grupos religiosos e invisibiliza a realidade social de indivíduos que não professam nenhuma religião.

Para Lurdes Caron, "em um mundo globalizado e de exclusão, é preciso investir na educação para a cidadania - a religiosidade é uma componente da vida do cidadão". Portanto, o ER como todas as disciplinas do currículo escolar, é responsável pela construção da nova cultura da solidariedade. ${ }^{15}$ Quanto à capacitação e o entendimento do professor de ER, a maioria (06 entrevistados) observam que o grande desafio na disciplina é o diálogo inter-religioso, o que exige controle e tato do professor, para não ofender qualquer religião ou praticar proselitismo.

No que diz respeito ao entendimento sobre o planejamento e/ou as ministrações de aula da disciplina de ER na educação pública estadual, embora dois entrevistados tenham respondido que conhecem alguns professores que trabalham de uma foram muito brilhante o fenômeno religioso, a maioria dos participantes (07 entrevistados) respondeu que este trabalho está sendo totalmente ignorado, ficando a cargo de cada professor. Cabe lembrar neste momento, que na educação pública estadual no Amapá, a regulamentação do Art. 33 da LDBEN através da Resolução no 14/2006-CEE/AP, preconiza um ensino baseado no "conhecimento humano com vista a subsidiar o aluno na compreensão do fenômeno religioso e do sagrado, presente nas diversas culturas e sistematizados por todas as tradições religiosas (...)" [Art. 2]. ${ }^{16}$

No que tange a diversidade religiosa, embora a interlocutora $C$ tenha respondido que o $E R$ contemplava a diversidade religiosa, onde a orientação era que o professor/a atentasse para essa diversidade em sala de aula, seis entrevistados afirmaram que não contemplava devido haver muito preconceito e discriminação contra as demais religiões não judaico-cristãs. Além disso, havia falta de PE para esta área de conhecimento, bem como muito proselitismo nas escolas públicas estaduais, principalmente pela carência de formação específica de professores/as de ER.

Concorda-se com Antônio Gomes da Costa Neto, quando afirma que esta situação é preocupante, pois uma educação sob o viés exclusivo do segmento cristão, por certo, não será um trabalho voltado para a diversidade religiosa, ou mesmo, o reconhecimento de outras práticas, será a manutenção do processo histórico da religião das maiorias, gerando, por via de consequência, a exclusão das demais. ${ }^{17}$

15 CARON, Lurdes. Políticas e Práticas Curriculares: Formação de professores ao Ensino Religioso. 2007. 354f. Tese [Doutorado em Educação]. Pontifícia Universidade Católica de São Paulo - PUC-SP, 2007. p. 137.

16 BRASIL, 2006.

17 COSTA NETO, Antônio Gomes da. Ensino religioso e as religiões matrizes africanas no Distrito Federal. 2010. 198f. Dissertação (Mestrado em Educação). Universidade de Brasília, Brasília, 2010. Disponível em: <http://repositorio.bce.unb.br/bitstream/10482/7083/1/2010AntonioGomesdaCostaNeto.pdf>. Acesso em: 29 out. 2011.

Protestantismo em Revista | São Leopoldo | v. 45, n. 02 | p. 37-48| Jul./dez. 2019

Disponível em: <http://periodicos.est.edu.br/index.php/nepp> 
Sobre a formação do professor/a de ER, em nossas pesquisas anteriores (2014) e atuais (2017) realizadas no Amapá não há cursos de licenciatura cadastrados e/ou autorizados para formar o professor/a do ER no Estado. O que existe é apenas cursos de bacharéis, cursos livres, de extensão ou de especialização para complementar a formação de professores/as de outras áreas no campo do ER. Com base nessas informações, percebe-se, portanto que o processo de formação do professor/a de ER no estado do Amapá é deficitário. ${ }^{18}$

Em entrevista no ano de 2012 junto a SEED, para coletar dados atualizados sobre a situação do quadro permanente de professores/as de ER das escolas estaduais, a Chefia da Unidade de Controle de Lotação (UCOLOM/SEED), havia nos respondido que naquele momento o quadro de servidores efetivos e temporários da SEED que atuavam no ER, era composto por 63 profissionais, onde a grande maioria não possuía formação específica na área do ER e sim na área de história, pedagogia, teologia, filosofia ou sociologia. ${ }^{19}$

Somos conhecedores de que o ER, bem como outras ciências assume um importante papel na reflexão, estudo e na prática educacional desenvolvendo vínculos entre os universos escolares, sociais e culturais. Para Edile Rodrigues e Sérgio Junqueira "O Ensino Religioso assume papel de favorecer a releitura do fenômeno religioso nacional, contextualizado e significativo para compreensão da sociedade brasileira". ${ }^{20}$ Desta forma, é fundamental inserir no currículo de ER, discussões e reflexões sobre temáticas enfrentadas no cotidiano escolar, bem como desenvolver processos de ensino e aprendizagem que abordem todas as leis e as demandas sócio educacionais.

Os Parâmetros Curriculares Nacionais para o Ensino Religioso (PCNER) têm encontrado no atual contexto social, antigo e novos desafios. O ER, como disciplina, tem uma das funções de despertar no educando aspectos transcendentes da existência, para a busca do sentido radical da vida, descobrindo-se como ser social consciente de ser parte de um todo. ${ }^{21}$ Neste sentido, o ER tem por objetivo estabelecer discussões sobre o Sagrado numa perspectiva laica, incentivando o diálogo inter-religioso e o respeito às diferentes formas de crer. Lembramos que de acordo com Célia Linhares, as práticas que reinventam a escola não resultam de opções estritamente pedagógicas, pois entrecruzam processos históricos, políticos, culturais, etc. ${ }^{22}$

\section{Percepções e ações sobre as religiões de matriz africana}

Em relação ao entendimento e/ou compreensão das RMA, quando questionados, os nove entrevistados divergiram em suas declarações. Para uns as RMA são manifestações culturais, para

18 CUSTÓDIO, Elivaldo Serrão. Formação do professor de ensino religioso no Amapá. In CUSTÓDIO, Elivaldo Serrão. SEMINÁRIO NACIONAL DE FORMAÇÃO DE PROFESSORES PARA O ENSINO RELIGIOSO, 12. 2012. Anais... Manaus-AM. 2012. p. 420-429. Disponível em: <www.gper.com.br/biblioteca_download.php?arquivold=880>. Acesso em: 16 nov. 2012; CUSTÓDIO, Elivaldo Serrão. Políticas públicas e direito ambiental cultural: as religiões de matrizes africanas no currículo escolar no Amapá, 2014, 198f. Dissertação (Mestrado em Direito Ambiental e Políticas Públicas) - Universidade Federal do Amapá, Macapá, 2014; CUSTÓDIO, Elivaldo Serrão, REIS, Marcos Vinícius de Freitas, BOBSIN, Oneide. A realidade do Ensino Religioso no Estado do Amapá: proposta de criação do primeiro curso de Licenciatura em Ciência da Religião. Estudos Teológicos, V. 57, N. 1 (2017). Disponível em: <http://periodicos.est.edu.br/index.php/estudos_teologicos/article/view/2958/pdf>. Acesso em: 10 fev. 2018.

${ }^{19}$ CUSTÓDIO, 2012.

20 RODRIGUES, Edile Maria Francaro; JUNQUEIRA, Sérgio Rogério Azevedo. Fundamentando pedagogicamente o Ensino religioso. Curitiba: IBPEX, 2009. p. 141.

21 JUNQUEIRA, Sérgio Rogério Azevedo. História, legislação e fundamentos do Ensino Religioso. Curitiba: IBPEX, 2008.

22 LINHARES, Célia. De uma cultura de guerra para uma cultura de paz e justiça social: movimentos instituintes em escolas públicas com processos de formação docente. In: LINHARES, Célia. LINHARES, Célia. ; LEAL, Maria Cristina. Formação Docente: uma crítica à razão e à política hegemônica. Rio de Janeiro: DP\&A, 2002. p. 103-130.

Protestantismo em Revista | São Leopoldo | v. 45, n. 02 | p. 37-48| Jul./dez. 2019

Disponível em: <http://periodicos.est.edu.br/index.php/nepp> 
outros seriam grupos de pessoas que tem uma forma diferente de crer e, ainda outros, entendem que se trata de manifestações religiosas que a partir do sagrado, da fé e dos ritos, suscitam relações com os princípios étnicos, valores humanos e relações de energia sobrenatural com o meio ambiente. Quando questionados, discorriam sobre o fato de que na educação pública estadual no Amapá, os problemas e/ou dificuldades em se trabalhar a questão das RMA no ER, em sua maioria tinha a ver com a formação profissional, infraestrutura, falta de planejamento, bem como desconhecimento das RMA como patrimônio cultural.

Com base nos depoimentos, acredita-se que se a posição perante as diferenças étnicoraciais ou a abordagem na escola não é uma tarefa fácil, dada a carga ideológica em relação ao tema. Entretanto, entende-se que pensar a educação como uma das possibilidades para enfrentar e superar qualquer forma de discriminação implica em propostas de PE que considerem a pluralidade étnica, racial e cultural de nossa sociedade; implica, ainda, por extensão, em uma mobilização envolvendo governos, educação/educadores/as, movimentos sociais, distintos atores sociais comprometidos com a promoção dos direitos humanos.

Para Jerome Bruner há necessidade de uma transformação da escola como uma cultura de aprendizagem, mas, também, de transformação do papel do professor nesta cultura da aprendizagem. ${ }^{23}$ Neste ponto, destaca-se a assimilação por parte dos/as professores/as de novas metodologias, incluindo também as questões étnico-culturais. Percebe-se nos depoimentos dos interlocutores uma cerca fragilidade em relação ao seu papel diante das questões étnicas raciais. No tocante aos representantes das RMA cadastrados na UOCUS conforme o que prevê a Resolução no 14/2006-CEE/AP constatou-se que não havia nenhuma entidade religiosa africana e/ou não judaico-cristã cadastrada no sistema de ensino estadual para discussão e/ou elaboração do Plano Curricular da Educação Básica do Estado do Amapá para a disciplina de ER. Ao perguntar-se aos entrevistados sobre esta situação, a interlocutora $\mathrm{C}$ respondeu que nunca foram convidados devido a comissão formada na UOCUS ser composta por pessoas vinculadas e/ou simpatizantes do modelo cristão. A afirmativa da interlocutora $C$, só vem reforçar a ideia de que o gerenciamento democrático somente se efetiva com a garantia de igualdade de condições de participação dos vários segmentos que compõem a sociedade, respeitados os seus diferentes saberes e suas diferentes opções religiosas.

Segundo a LDBEN de 1996 e a sua alteração em 1997 o planejamento curricular dos sistemas de ensino, devem abrir espaço em sua composição para entidades religiosas diversas. Entretanto, para a confirmação de nossa hipótese, a maioria dos entrevistados (08) respondeu que: reconhecem que no estado do Amapá há grandes nomes e referências das RMA, que observam que em algumas situações específicas, estas entidades são convidadas para participarem em eventos e/ou celebrações promovidas por entidades públicas educacionais; esclarecem que desconhecem que representantes das RMA, em algum momento da história amapaense, tenham participado da discussão e/ou elaboração do Plano Curricular da Educação Básica do Estado do Amapá. Em relação à presença das RMA na disciplina de ER na educação pública da rede estadual, um dos entrevistados (interlocutor F) respondeu que elas estão presentes, de acordo com a formação profissional de cada professor/a que atua na sala de aula. Além do mais, há uma deficiência também das RMA no currículo da disciplina de ER, por parte daqueles que ministram este ensino.

Um outro entrevistado (interlocutor $\mathrm{H}$ ) respondeu que essas representações religiosas estão presentes somente nas simples demonstrações, em contextos históricos apresentados em momentos específicos, como por exemplo, por ocasião da Semana Nacional da Consciência Negra

23 BRUNER, Jerome. A cultura da educação. Porto Alegre: Artemed, 2001. p. 85.

Protestantismo em Revista | São Leopoldo | v. 45, n. 02 | p. 37-48| Jul./dez. 2019

Disponível em: <http://periodicos.est.edu.br/index.php/nepp> 
no mês de novembro. Entretanto, a maioria dos entrevistados respondeu com bastante ênfase que a ausência é total. Além do mais, o que eles têm observado em muitas escolas, são professores/as preconceituosos/as que não tem atribuído o devido respeito e valorização a estas manifestações religiosas. É interessante ressaltar sobre a análise desta questão, que um dos entrevistados (interlocutor I) embora tenha afirmado a ausência das RMA na disciplina de ER, destacou que isso se dá também pela falta dos próprios "pais de santo" que não participam de atividades culturais e religiosas nas escolas, sentem medo de serem ignorados ou discriminados pela comunidade escolar. A representante da APERAP (interlocutora E), ao se expressar sobre sua experiência como professora da disciplina de ER, relatou-nos sua angústia enquanto educadora e militante do ER no Amapá. Vejamos um trecho da entrevista:

[...] Te digo uma coisa muito forte, eu mesma como professora de ensino religioso e de história [...] foram três escolas por onde eu passei. E eu atribuo a essa minha transição, essa minha mobilidade, é pela defesa que eu faço das religiões de matriz africana, pelo trabalho que eu desenvolvo com as religiões de matriz africana e isso é muito difícil pra ser aceito dentro do espaço escolar, os outros professores de outras disciplinas junto com as equipes técnicas, junto com os diretores e os demais funcionários, eles nos olham quando a gente trabalha com a disciplina de matriz africana de uma forma completamente discriminatória [Enfática]. Eles te veem como o próprio demônio ali. Eu senti isso na pele e falo com muito pesar [...] Eu trabalho cristianismo, eu trabalho budismo, e trabalho as religiões de matriz africana da mesma forma, com o mesmo respeito e quero que meu aluno compreenda isso. [Enfática]. A coisa mais fantástica que eu posso te dizer dessa minha experiência é que eu não tenho problemas com os alunos. Os alunos não se recusam a entender, a compreender, a ler, a fazer desenhos dos deuses africanos, a fazer cartazes e pregar na parede. Agora eu sinto isso em relação aos professores, eu sinto em relação à administração escolar [...] (INTERLOCUTORA E).

Sobre a questão do racismo na escola, concorda-se com Eugènia Foster quando declara que a questão do racismo na escola brasileira é sutil e complexa. Entretanto, percebe que na realidade amazônica parece mais sutil e complexa ainda, pois "o racismo não se apresenta somente em uma dimensão. Ele envolve uma interdependência de fatores que, juntos, lhe dão a face que o caracteriza". ${ }^{24}$ As falas revelam indícios de que na visão dos entrevistados a presença das RMA na disciplina de ER das escolas públicas estaduais amapaenses ainda é tratada do ponto de vista somente da cultura. Para o representante do NEER há uma inversão de valores, pois o ensino da afro religiosidade está adentrando pelas escolas através de projetos culturais e não como religião compostas de seus ritos, elementos sagrados, valores, etc. Segundo o representante do NEER existe um tabu de aceitar a diversidade religiosa como religião. Inclusive isso tem sido uma estratégia dos técnicos dessa entidade no desenvolvimento de ações educacionais nas escolas públicas.

\section{Considerações finais}

Ao longo desta pesquisa procurou-se demonstrar que no Brasil, em especial no estado do Amapá, não se respeita plenamente o Princípio da Laicidade. Entende-se que os representantes de religiões não judaico-cristãs devem participar da discussão e elaboração do Plano Curricular da Educação Básica do Estado do Amapá. Da mesma forma, os professores/as que trabalham com o ER, devem ser submetidos a programas de formação superior e/ou formação continuada voltada para a área do ER. As falas dos sujeitos da pesquisa evidenciam uma variedade de opções de

24 FOSTER, Eugènia da Luz Silva. Racismo e Movimentos Instituintes na Escola. Niterói: 2004. 398f. [Tese Doutorado] Faculdade de Educação, Universidade Federal de Fluminense, Rio de Janeiro, 2004. p. 357.

Protestantismo em Revista | São Leopoldo | v. 45, n. 02 | p. 37-48| Jul./dez. 2019

Disponível em: <http://periodicos.est.edu.br/index.php/nepp> 
trabalho sobre o ER e as RMA na educação pública estadual no Amapá, ora revelando um discurso inovador, ora refletindo práticas tradicionais, conservadoras ou proselitistas. Verificou-se que a discussão das RMA no ER, do ponto de vista prático, é inexistente e não contemplada no currículo da disciplina, na formação dos docentes, nas orientações pedagógicas, cujos ensinamentos estão delineados sob o viés cristão, sem qualquer alusão às práticas antirracistas.

Percebeu-se ainda nas falas dos entrevistados que aqueles que têm suas trajetórias de vida ou profissional marcadas por relações de proximidade com práticas religiosas de RMA apresentam um maior grau de abertura para propor o diálogo sobre essas temáticas durante seu trabalho técnico e/ou pedagógico. Com relação à diversidade cultural, observou-se que ela tem sido crescente no Brasil, com apresentação de diferentes formas de pensar e agir. Com relação à diversidade religiosa, este assunto tem sido mais complexo ainda. Verificou-se que as leis elaboradas para o ER, bem como os materiais utilizados neste ensino, sempre sofreram a interferência, em sua maioria, do cristianismo.

Há indícios de que a diversidade religiosa não tem sido considerada dentro das ações dos órgãos oficiais do governo e que há grandes dificuldades em se concretizar um diálogo concreto. Muitos técnicos/as e gestores/as desconhecem os elementos que compõem o fenômeno religioso e o papel das tradições religiosas nas sociedades, portanto é evidente a falta de compreensão do ER como disciplina e como área de conhecimento. A diversidade que é proposta pelo Estado e que vem sendo constantemente evidenciada nos documentos oficiais parece estar alicerçada na ideia de acervo cultural, tomando como base as influências culturais diversas. Contudo, a pesquisa de campo, constatou que importantes entidades religiosas são deixadas de lado como as RMA no ER.

Percebeu-se que a COODNOPE, o NATEP, o NEER e a UOCUS criadas, com a finalidade de nortear a Educação do Estado do Amapá no que tange à diversidade religiosa, trata-se de mais um grupo de trabalho que não está livre do jogo do poder, por não contemplar o reconhecimento da identidade cultural religiosa brasileira, ou mesmo apresentar qualquer proposta significativa de trabalho para "ouvir" as diversas organizações religiosas. Entende-se com isso, que sem a valorização e o respeito às RMA no ER e no Ensino da Cultura e História da África e dos Afrobrasileiros não prevalecerá o dispositivo legal na preservação e valorização da cultura. $O$ diálogo com os entrevistados deixa transparecer que, enquanto não houver interação entre as esferas governamentais e não governamentais nos processos de elaboração, execução e implementação de PE reais com práticas concretas, não haverá mudanças estruturais significativas na educação pública, nem tão pouco, melhoras na qualidade do ensino e o atendimento às exigências de uma educação étnico racial.

Enfim, diante destas questões, acredita-se que a SEED juntamente com as entidades entrevistadas, devam atentar às demandas educacionais contemporâneas que têm suporte na concepção de igualdade, na multidisciplinaridade e na diversidade étnico-racial. Assumindo assim, um maior compromisso com a reorientação curricular da educação amapaense, na formação inicial e continuada de educadores/as, na revisão das metas orçamentárias e na criação de uma gestão pública democrática e efetivamente inclusiva.

\section{Referências}

AITH, Fernando. Políticas públicas de Estado e de governo: instrumentos de consolidação do Estado Democrático de Direito e de promoção e proteção de direitos humanos. In: BUCCl, Maria Paula Dallari (Org.) Políticas Públicas: reflexões sobre o conceito jurídico. São Paulo: Saraiva, 2006, p. 217-246.

Protestantismo em Revista | São Leopoldo | v. 45, n. 02 | p. 37-48| Jul./dez. 2019

Disponível em: <http://periodicos.est.edu.br/index.php/nepp> 
BOURDIEU, Pierre; PASSERON, Jean-Claude. A reprodução: elementos para uma teoria do sistema de ensino. Tradução de Reynaldo Bairão. 3. ed. Petrópolis, RJ: Vozes, 2008.

BRASIL. Constituição (1988). Constituição da República Federativa do Brasil. Brasília, 1988.

BRASIL. Lei n. 9 9.394, de 20 de dezembro de 1996. Brasília, 1996. Estabelece as diretrizes e bases da educação nacional. Disponível em: <http://www.planalto.gov.br/ccivil_03/Leis/L9394.htm>. Acesso em: 09 mar. 2011.

BRASIL. Lei no 9.475, de 22 de julho de 1997. Brasília, 1997. Dá nova redação ao art. 33 da Lei no 9.394, de 20 de dezembro de 1996, que estabelece as diretrizes e bases da educação nacional. Disponível em: <http://www.planalto.gov.br/ccivil03/Leis/L9475.htm>. Acesso em: 09 mar. 2011.

BRASIL. Lei no 10.639, de 09 de janeiro de 2003. Brasília, 2003. Instituiu a obrigatoriedade do ensino de História e Cultura Afro-brasileira e Africana no Currículo da Educação Básica. Disponível em: <http://www.planalto.gov.br/ccivil03/Leis/2003/L10.639.htm>. Acesso em: 01 out. 2011.

BRASIL. Resolução no 14/2006 de 15 de março de 2006. Amapá, 2006. Conselho Estadual de Educação do Amapá Dispõe sobre a oferta do ensino religioso no nível fundamental, do sistema educacional do Estado do Amapá. Disponível em: <http://www.gper.com.br/bibliotecadownload.php?arquivold=136>. Acesso em: 28 ago. 2011.

BRONCKART, Jean-Paul. Atividades de Linguagens, texto e discursos. Por um interacionismo sócio discursivo. Trad. Anna Rachel Machado e Péricles Cunha. São Paulo: Educ, 1997.

BRUNER, Jerome. A cultura da educação. Porto Alegre: Artemed, 2001.

BUCCl, Maria Paula Dallari. O conceito de política pública em direito. In: BUCCI, Maria Paula Dallari. Políticas Públicas: reflexões sobre o conceito jurídico. São Paulo: Saraiva, 2006, p. 01-50.

CARON, Lurdes. Políticas e Práticas Curriculares: Formação de professores ao Ensino Religioso. 2007. 354f. Tese (Doutorado em Educação). Pontifícia Universidade Católica de São Paulo - PUC-SP, 2007.

COSTA NETO, Antônio Gomes da. Ensino religioso e as religiões matrizes africanas no Distrito Federal. 2010. 198f. Dissertação (Mestrado em Educação). Universidade de Brasília, Brasília, 2010.

CUSTÓDIO, Elivaldo Serrão. Formação do professor de ensino religioso no Amapá. In CUSTÓDIO, Elivaldo Serrão. SEMINÁRIO NACIONAL DE FORMAÇÃO DE PROFESSORES PARA O ENSINO RELIGIOSO, 12. 2012. Anais... Manaus-AM. 2012. p. 420-429. Disponível em: www.gper.com.br/biblioteca download.php?arquivold=880. Acesso em: 16 nov. 2012.

CUSTÓDIO, Elivaldo Serrão. Políticas públicas e direito ambiental cultural: as religiões de matrizes africanas no currículo escolar no Amapá, 2014, 198f. Dissertação (Mestrado em Direito Ambiental e Políticas Públicas) - Universidade Federal do Amapá, Macapá, 2014.

CUSTÓDIO, Elivaldo Serrão. Ministério da Educação (MEC). Base Nacional Comum Curricular, Brasília: 2018.

CUSTÓDIO, Elivaldo Serrão; REIS, Marcos Vinícius de Freitas; BOBSIN, Oneide. A realidade do Ensino Religioso no Estado do Amapá: proposta de criação do primeiro curso de Licenciatura em Ciência da Religião. Estudos Teológicos, V. 57, N. 1 (2017). Disponível em: $<$ http://periodicos.est.edu.br/index.php/estudos teologicos/article/view/2958/pdf >. Acesso em: 10 fev. 2018.

DEMO, Pedro. Metodologia Científica em ciências sociais. 3. ed. São Paulo: Atlas, 2009.

Protestantismo em Revista | São Leopoldo | v. 45, n. 02 | p. 37-48| Jul./dez. 2019 Disponível em: <http://periodicos.est.edu.br/index.php/nepp> 
DENZIN, Norma K.; LINCOLN, Yvonna S. Introdução: a disciplina e a prática da pesquisa qualitativa. In: DENZIN, Norma K. O planejamento da pesquisa qualitativa: teorias e abordagens. 2. ed. Porto Alegre: Artmed, 2006. p. 15-41.

FOSTER, Eugènia da Luz Silva. Racismo e Movimentos Instituintes na Escola. Niterói: 2004. 398f. Tese (Doutorado) - Faculdade de Educação, Universidade Federal de Fluminense, Rio de Janeiro, 2004.

FOUCAULT, Michel. A ordem do discurso: Aula inaugural no Collège de France, pronunciada em 02 de dezembro de 1970. 16. ed. Tradução de Laura Fraga de Almeida Sampaio. São Paulo: Loyola, 2008.

JUNQUEIRA, Sérgio Rogério Azevedo. História, legislação e fundamentos do Ensino Religioso. Curitiba: IBPEX, 2008.

LINHARES, Célia. De uma cultura de guerra para uma cultura de paz e justiça social: movimentos instituintes em escolas públicas com processos de formação docente. In: . LINHARES, Célia.; LEAL, Maria Cristina. Formação Docente: uma crítica à razão e à política hegemônica. Rio de Janeiro: DP\&A, 2002. p. 103-130.

RODRIGUES, Edile Maria Francaro; JUNQUEIRA, Sérgio Rogério Azevedo. Fundamentando pedagogicamente o Ensino religioso. Curitiba: IBPEX, 2009.

SEVERINO, Antônio Joaquim. Metodologia do trabalho científico. 23. ed. São Paulo: Cortez, 2007.

SILVA, Tomaz Tadeu. Documentos de identidade: Uma introdução às teorias do currículo. 3. ed. Belo Horizonte: Editora Autêntica, 2003.

VIANA, Larissa. O Idioma da mestiçagem: as irmandades de pardos na América Portuguesa. Campinas, SP: Editora da UNICAMP, 2007. 